\title{
Letter to the Editor: Gratitude and Good Outcomes: Rediscovering Positivity and Perspective in an Uncertain Time
}

\author{
Sergey Minaev ${ }^{1}$ (D) Vitaly Schetinin $^{2} \cdot$ Igor Kirgizov $^{3} \cdot$ Alina Grigorova $^{1} \cdot$ Michael Akselrov $^{4}$. \\ Igor Gerasimenko ${ }^{1}$
}

Accepted: 15 October 2021/Published online: 8 November 2021

(C) Société Internationale de Chirurgie 2021

\section{Dear Editor,}

We are grateful to W.T. Shen and J.A. Sosa for their stimulating discussion of features and development strategies in surgery [1]. The authors emphasize that surgery is a "team sport" that requires the expertise, dedication, and input of multiple other team members. However, in modern conditions, difficulties have arisen in the preparation of professional skills and approaches to motivate doctors and nurses. According to experts, the outlined strategies must consider the COVID-19 pandemic, which has caused changes in the training of young surgeons [2].

Extremely important for the surgeon is the study of the peer-reviewed literature. Reading articles from the Internet via handheld devices has become a modern reality. When accessed in this way, commercial and advertising articles appear in the first lines of search results; it is not surprising in a search list to find an article that reports subjective or even misleading assessments and findings. Therefore, it becomes critical to find an article providing a qualified evaluation provided by an expert in a specific field. In this situation, the role of online social networks in article citations becomes important, as noted in Grossman et al. [3]. This point is particularly essential for young professionals who use Internet platforms such as Facebook,

Sergey Minaev

sminaev@yandex.ru

1 Stavropol State Medical University, 310 Mira Str., Stavropol, Russia 355017

2 School of Computer Science and Technology, University of Bedfordshire, Luton LU1 3JU, UK

3 Russian Medical Academy of Continuing Professional Education, Moscow, Russia

4 Tyumen State Medical University, Tyumen, Russia
Twitter, and Instagram. A significant contribution to disseminating the top-ranked publications via Twitter is now being made by open-access journals and professional associations for surgeons, as well as by individual bloggers and hashtags. For example, a hashtag such as \#SoMe4Surgery, indicating publications in all surgery sections, is used by more than 5,000 surgeon subscribers.

The main focus in the training of young surgeons is the development of manual skills. Today such training relies on simulators and simulation centres. Generation $\mathrm{Z}$ surgeons now face two specific problems: (i) difficulties in locating the pathology in the organ and (ii) difficulties in conducting a surgical procedure with an atypical site of cyst/tumour. To directly address these specific problems, we have begun using three-dimensional (3-D) simulation of pathological cases. For example, 3-D modelling of cystic liver damage could include the following stages:

1. creating a computer 3-D reconstruction of a liver with a cyst from the computed tomography (CT) scan, as described in Schetinin et al. [4];

2. printing a 3-D model of the liver with a cyst and topical arrangement of vascular structures and a biliary tract on a high-quality 3-D printer [5]; and

3. practising a laparoscopic technique for removing the liver cyst with the optimal installation of laparoscopic ports based on a simulation centre of practical skills.

This approach has allowed us to improve the development of the required surgical skills while significantly decreasing the time commitment of the instructor or experienced surgeon.

Finally, we believe that in addition to the gains in knowledge resulting from improved access to high-quality surgery articles with unbiased search results, the use of 3-D 
modelling will help develop the required skills and shape a new approach to training young surgeons.

Funding The study was not sponsored.

\section{Declarations}

Conflict of interest The authors declare no conflicts of interest.

\section{References}

1. Shen WT, Sosa JA (2020) Gratitude and good outcomes: rediscovering positivity and perspective in an uncertain time.
World J Surg 44:2848-2849. https://doi.org/10.1007/s00268-02005649-1

2. Behrns KE, Wexner SD (2021) New features Surgery. Surgery 169(2):707. https://doi.org/10.1016/j.surg.2021.01.001

3. Grossman R, Sgarbura O, Hallet J et al (2021) Social media in surgery: evolving role in research communication and beyond. Langenbeck's Arch Surg 406:505-520. https://doi.org/10.1007/ s00423-021-02135-7

4. Schetinin V, Jakaite L, Krzanowski W (2018) Bayesian averaging over Decision Tree models for trauma severity scoring. Artif Intell Med 84:139-145. https://doi.org/10.1016/j.artmed.2017.12.003

5. Minaev SV, Gerasimenko IN, Grigorova AN et al (2020) 3Dtechnologies in hepatobiliary surgery. Khirurgiia (Mosk) 8:103-106. https://doi.org/10.17116/hirurgia2020081103

Publisher's Note Springer Nature remains neutral with regard to jurisdictional claims in published maps and institutional affiliations. 